\title{
Regional sustainable development assessment for an air quality index system: a case study of the Macau Special Administration Region
}

\author{
Y. Ge ${ }^{1}$, I. Lou ${ }^{1}$, H. Zheng ${ }^{1} \&$ Z. Wang ${ }^{2}$ \\ ${ }^{1}$ Department of Civil and Environmental Engineering, \\ Faculty of Science and Technology, University of Macau, China \\ ${ }^{2}$ Research Centre of Environmental Science and Management, \\ Macau University of Science and Technology, China
}

\begin{abstract}
Macau is a typical coastal city with limited land resources, in need of sustainable development, based on the creative conjunctions of ecological, social and economic aspects. With the development of Hengqin Island and the Hong Kong-Zhuhai Macau bridge, Macau is standing at a new historical starting point and facing new opportunities for further development. The regional sustainable development index assessment for outdoor air quality control (RSIAC) cannot only support decision-making with multiple objectives, but also provide discussions and figure out the potentials in urban sustainable development in the future. This paper advances the understanding of Macau sustainable development, through an in-depth analysis of an outdoor air quality dimension. In this study, a system approach is adopted, which integrates the analytic hierarchy process and principal components analysis. The three pillars of sustainability (economic, social and environmental) are modelled, estimated and incorporated into a concept - the regional characteristic sustainability. RSIAC application shows that the index is feasible and forms an important contribution to the ongoing discourse on regional sustainable development evaluation adaptation in the Macau Special Administration Region.

Keywords: sustainable development index, outdoor air quality control.
\end{abstract}




\section{Introduction}

The sustainable development concept was first brought to public discussions in the 'Our Common Future' (Brundtland Report), and the sustainability is accepted and defined as "development that meets the needs of the present without compromising the ability of future generations to meet their own needs" (WCED, 1987). The definition provided by the Brundtland Report is a characteristic definition of sustainability [1]. Later, in the second United Nations Conference on Environment and Development held in Rio de Janeiro in 1992, there was a breakthrough in the discussion of sustainability among nations. The objectives of sustainable development are well-accepted as a triple-bottom-line (TBL) undertaking that requires achieving environmental, economic, and social prosperity simultaneously [2]. Through the concept of the triple-bottom line, the relationship between perpetuity of ecosystems, economic development and life quality is more abstractly interpreted.

The Brundtland Report instigated that the worldwide political support for sustainable development. Within the last decades, various indicators-based sustainability assessment approaches for regional development have been advanced and discussed, e.g., Ecological Footprint (EF), Environmental Sustainability Index (ESI), Dashboard of Sustainability (DS), Environmental Impact Assessment (EIA), Integrated Assessment, Welfare Index, Genuine Progress Indicator (GPI), Index of Sustainable Economic Welfare, City Development Index, Human Development Index (HDI), Environmental Vulnerability Index (EVI), Environmental Policy Index (EPI), Living Planet Index (LPI), Environmentally-adjusted Domestic Product (EDP), Genuine Saving (GS). There is no doubt that these assessments tools play an important role in providing local authorities with guidance toward sustainable path. As Devuyst [3] said, sustainability assessment is a tool that can help decision-makers and policymakers decide which actions they should or should not take in an attempt to make society more sustainable [3]. However, these approaches show deficits with respect to the indicator selections considering the sensitive balance of variety and unity.

Macau is one of the special administration regions of China after 1999, has an increased awareness of the need for continuous growth and sustainable development. As a world famous tourist city, Macau nowadays faces a lot of sustainable development challenges due to its natural weakness such as short on land resources, high density of population and low environmental assimilation capacity. How to protect, develop, and improve the living environment, be in harmony with its development in both economic, social and environmental benefit, close up to the sustainable development direction is a major task for the government and citizens.

\section{Study objectives, methodology and result}

Macau's economy has been in the transformation stage since the implementation of the " $12^{\text {th }}$ Five-Year Plan". The adjustment for economic structure and industrial 
structure must affect the Macau city sustainable development process [4]. For the transition to sustainability, goal must be assessed. Therefore, there is the need to provide an efficient but reliable tool to respond to challenges in the scientific community. Sustainability assessment has become a rapidly developing area. The aim of this paper is to contribute to RSIAC by providing a transparent assessment procedure to support decision-making in Macau. Based on an inventory of different tools for assessing sustainability, material used consisted not only of literature describing each of the tools, but also material related to the specific application of each of the assessment approaches. Figure 1 illustrates the assessment metric of RSIAC.

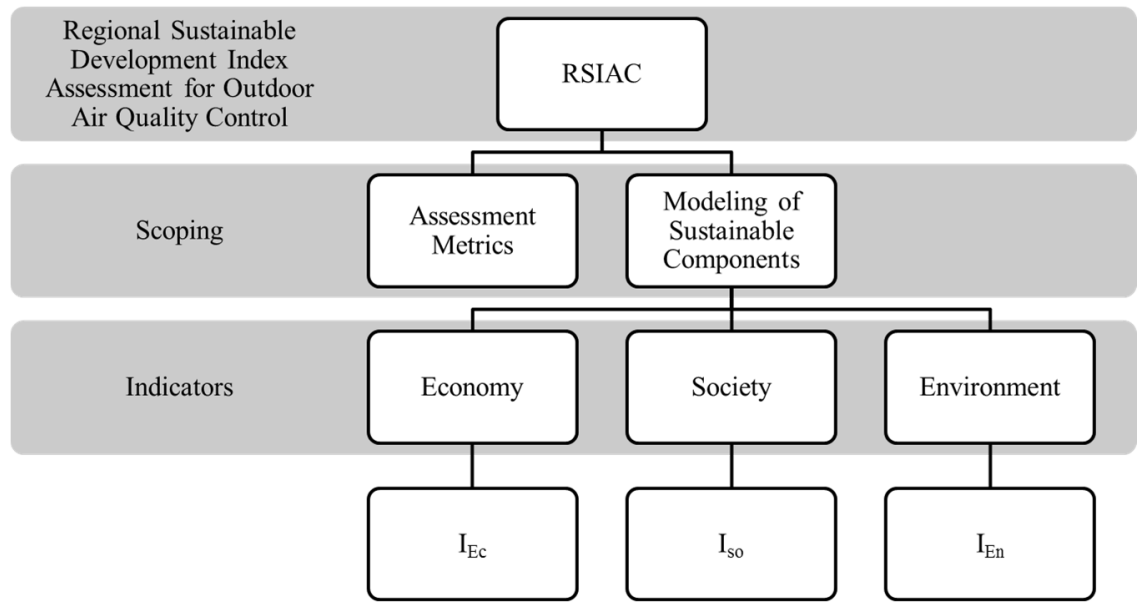

Figure 1: RSIAC framework.

Since the concept of sustainable development is not one dimensional, various discussing exist regarding various aspects of the concept [5]. Indicators are simple measures which can be quantified and represent a state of economic, social and environmental development in a defined area. When indicators are aggregated in some manner, the resulting measure is an index. To easily and rapidly understand sustainable development progress, sustainability indicators should be simplified to produce a sustainability index [6]. It is helpful to assist decision-makers in understanding the problems with existing station and defining specific objectives and measuring progress towards sustainable development strategy.

Various multi-criteria decision-making (MCDM) techniques have been widely used in the assessment area. Analytic hierarchy process (AHP) is a common MCDM technique that can be used to assign relative weights to various sustainability criteria and aggregate those estimates to determine an arbitrary measure or index of sustainability [7]. The AHP provides an organized description of the hierarchical interaction or connection among the elements (impacts, criteria or alternatives). It always begins with a goal statement and then develops a decision tree through top to bottom [8]. Principle components analysis (PCA) is a 
multivariate statistical technique used to reduce the number of variables in a data set into a smaller number of 'dimensions'. In mathematical terms, from an initial set of $\mathrm{n}$ correlated variables, PCA creates uncorrelated indices or components, where each component is a linear weighted combination of the initial variables [9].

This study uses an integrated framework of AHP and PCA in the selection of sustainability assessment of outdoor air quality in Macau. TBL sustainability criteria in the studying areas - environmental, economic, and social were applied in the analysis. Each dimension carries the same weight, by using TBL main criteria that were further divided into following eleven second grade (Table 1):

Table 1: The RSIAC-Macau system.

\begin{tabular}{|c|c|c|c|c|}
\hline & First Grade & Weights & Second Grade & No. \\
\hline \multirow{4}{*}{ RSIAC } & \multirow[t]{4}{*}{ Economic } & \multirow[t]{4}{*}{$1 / 3$} & Environmental protection investment & Ec1 \\
\hline & & & Environmental protection and energy saving fund & Ec2 \\
\hline & & & GDP per capita & Ec3 \\
\hline & & & Environmental assets & Ec4 \\
\hline \multirow[t]{7}{*}{ Macau } & \multirow[t]{4}{*}{ Social } & \multirow[t]{4}{*}{$1 / 3$} & Population density ('000/km²) & So1 \\
\hline & & & Motor vehicles density (No./km) & So2 \\
\hline & & & Days with good air quality $(0-50)$ & So3 \\
\hline & & & Days with poor air quality (101-200) & So4 \\
\hline & \multirow[t]{3}{*}{ Environmental } & \multirow[t]{3}{*}{$1 / 3$} & $\mathrm{SO}_{2}$ emission per capita & En1 \\
\hline & & & $\mathrm{NO}_{2}$ emission per capita & En2 \\
\hline & & & $\begin{array}{l}\text { Respirable suspended particulates }\left(\mathrm{PM}_{10}\right) \\
\mathrm{d}<10 \mu \mathrm{m}\end{array}$ & En3 \\
\hline
\end{tabular}

In order to estimate the sustainability assessment (S) of RSIAC including the three pillars of sustainability (economic (Ec), social (So) and Environmental (En)), the following equation as a function of sustainability dimensions is given:

$$
S=\left\{\begin{array}{l}
E c \\
S o \\
E n
\end{array}\right\}=f(E c, S o, E n)
$$

eqn (1) can be rewritten as the following eqn (2) and eqn (3). Each term in eqn (3) represents a value of sustainability of each individual dimension. Adding these terms with relative weights is shown in Table 1.

$$
\begin{gathered}
S=\sum_{K=1}^{n_{S}=3} w_{k_{-} S} I_{K_{-} S} \\
S=w_{E c}\left(I_{E c}\right)+w_{S o}\left(I_{S o}\right)+w_{E n}\left(I_{E n}\right)
\end{gathered}
$$


where $\mathrm{S}=$ sustainability assessment regarding RSIAC. Note that $\mathrm{S}$ may be equal to one or less than one or more than one. $\mathrm{W}_{\mathrm{K}_{\mathrm{S}}}$ is the relative weight of issue $\mathrm{k}$ regarding sustainability $(\mathrm{S})$; $\mathrm{I}_{\mathrm{K}_{-} \mathrm{S}}$ is the value of attribute of issue $\mathrm{k}$ regarding sustainability $(\mathrm{S}) ; \mathrm{I}_{\mathrm{Ec}}$ is the value of attribute of economic issues (Ec) regarding sustainability $(\mathrm{S})$; $\mathrm{I}_{\mathrm{So}}$ is the value of attribute of social issues (So) regarding sustainability $(\mathrm{S})$; and, $\mathrm{I}_{\mathrm{En}}$ is the value of attribute of environmental issues $(\mathrm{En})$ regarding sustainability $(\mathrm{S})$.

The $\mathrm{w}_{\mathrm{Ec}}, \mathrm{w}_{\mathrm{S} o}$ and $\mathrm{w}_{\mathrm{En}}$ are the relative weights of the economic issues, social issues and environmental issues, respectively. Because trade-offs frequently exist between these objectives, a comprehensive analysis for each individual measure is needed.

$$
A_{s}=\left[\begin{array}{ccc}
1 & \frac{w_{E c}}{w_{S o}} & \frac{w_{E c}}{w_{E n}} \\
\frac{w_{S o}}{w_{E c}} & 1 & \frac{w_{S o}}{w_{E n}} \\
\frac{w_{E n}}{w_{E c}} & \frac{w_{E n}}{w_{S o}} & 1
\end{array}\right]
$$

Based on the methodology mentioned above, after using the AHP calculation tool, the weight of the each dimension with its percentage of Macau RSIAC is presented in the Figure 2. It can be noticed from the figure, the respirable suspended particulates (PM10) represent the highest value $(25 \%)$ in the whole evaluation system. This means that PM10 is the most significant point in the process of dealing with air quality issues. To improve the quality of life, awareness of the atmospheric environment protection investment and fund will be its priority important position.

The mathematical model of the sustainability either economic or social or environmental individually, is presented in the following eqn (5), where $I_{K}$ is the sustainability of major pillar (e.g. economical (Ec) or social (So) or environmental (En)). I $i$ stands for the sustainability of major issue or aspect $\mathrm{i}$ in major pillar $\mathrm{K}$.

$$
I_{K}=f\left(I_{i}\right)
$$

Eqn (6) is used to estimate the sustainability assessment regarding economic or social or environmental sustainability based on the relative weights to estimate the sustainability index, where $\mathrm{w}_{\mathrm{i}_{\mathrm{K}} \mathrm{K}}$ is the relative weight regarding major aspects or issues $\mathrm{i}$ of major pillar $\mathrm{K}$, and $\mathrm{I}_{\mathrm{i}_{-} \mathrm{K}}$ is the value of attribute regarding major aspects or issues i of major pillar K.

$$
I_{K}=\sum_{i=1}^{n_{i}} w_{i_{-} K} I_{i_{-} K}
$$


68 Sustainable Development, Vol. 1

Decision Hierarchy

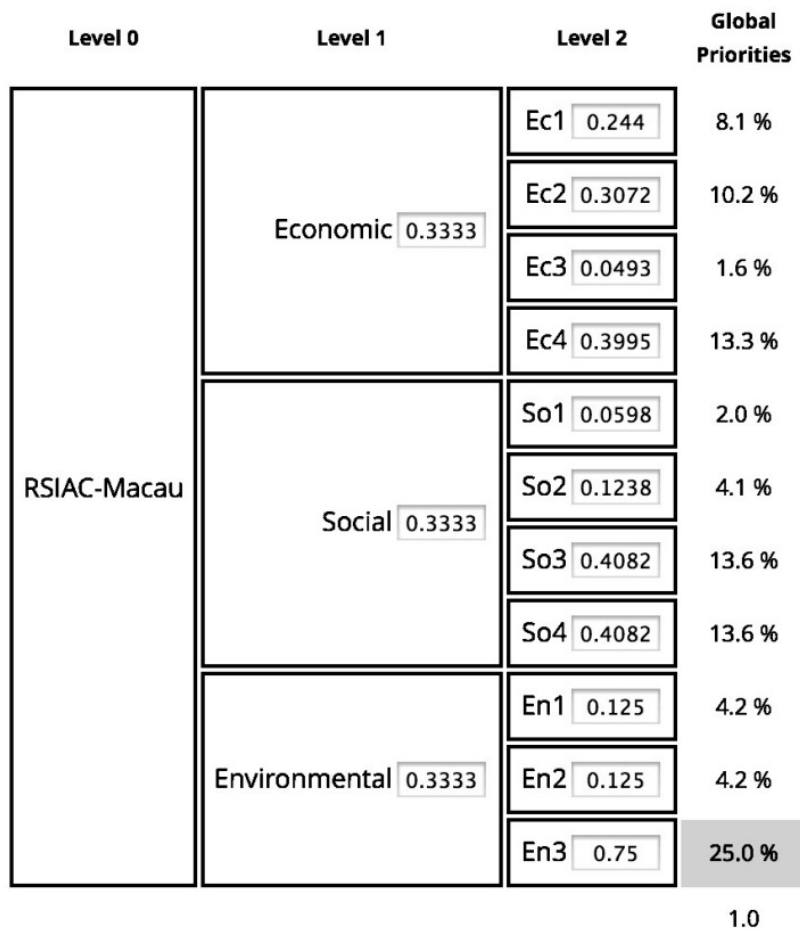

Figure 2: Indicator weight in Macau RSIAC.

Therefore, the sustainability indexes for economy, society and environment aspects are evaluated according to the following eqns (7)-(9), respectively. $\mathrm{n}_{\mathrm{i}_{-} \mathrm{Ec}}$ presents the number of major issues in economic aspect, $n_{i_{-} \text {so }}$ is the number of major issues in social aspect, and $n_{i_{-} E n}$ is the number of major issues in environmental aspect.

$$
\begin{gathered}
I_{E c}=\sum_{i=1}^{n_{i-E c}} w_{i_{-} E c} I_{i_{-} E c} \\
I_{S o}=\sum_{i=1}^{n_{i-S o}} w_{i_{-} S o} I_{i_{-} S o} \\
I_{E n}=\sum_{i=1}^{n_{i-E n}} w_{i_{-} E n} I_{i_{-} E n}
\end{gathered}
$$


In this study, we compared five years development pathway, and the optimum value of each dimension is regarded as the benchmark. In eqns (10)-(12), $\mathrm{I}_{\mathrm{ij}}$ presents performance metric of aspect $\mathrm{j}$ in major issue $\mathrm{i}$ representing ratio between towards the sustainability $(S)$ and the existing $(E) . S_{i j}$ is the value of aspect $\mathrm{j}$ in major issue $i$ towards the sustainability $(S)$ (benchmarking). $E_{i j}$ equals to the value of aspect $\mathrm{j}$ in major issue $\mathrm{i}$ regarding the existing (E) status.

$$
\begin{array}{cc}
I_{i j}=\frac{S_{i j}}{E_{i j}} & \left(S_{i j}<E_{i j}\right) \\
I_{i j}=1 & \left(S_{i j}=E_{i j}\right) \\
I_{i j}=\frac{E_{i j}}{S_{i j}} & \left(S_{i j}>E_{i j}\right)
\end{array}
$$

For the modelling of RSIAC-Macau, due to lack of global criterion for the selected indicators, each indicator uses the best value as the benchmark. In order to unify the value between different samples, the benchmark for each indicator is considered as 1 . The others can be presented as the ratio to the benchmark. If the existing value towards the benchmark of sustainability is smaller, the eqn (12) is used for the ratio calculate. On the other hand, if the existing value towards the benchmark is bigger, the eqn (10) is used. After that we can get a set of unified indicators value for the sustainable development related aspects. Table 2 and Table 3 demonstrate the application of the proposed method, from the data collection

\begin{tabular}{|c|c|c|c|c|c|c|}
\hline Second Grade & No. & 2003 & 2008 & 2011 & 2012 & 2013 \\
\hline $\begin{array}{l}\text { Environmental protection } \\
\text { investment ('000 mop) }\end{array}$ & Ec1 & 351784.0 & 670709.0 & 738713.0 & 616625.0 & 760887.0 \\
\hline $\begin{array}{l}\text { Environmental protection } \\
\text { and energy saving fund } \\
\text { ('000 mop) }\end{array}$ & Ec2 & - & - & 450.0 & 57112.0 & 111765.0 \\
\hline GDP per capita & Ec3 & 17809.0 & 38391.0 & 66687.0 & 75532.0 & 87306.0 \\
\hline $\begin{array}{l}\text { Environmental asset s('000 } \\
\text { mop) }\end{array}$ & Ec4 & 3523.0 & 21766.0 & 89514.0 & 51730.0 & 30549.0 \\
\hline $\begin{array}{l}\text { Population density } \\
\left(' 000 / \mathrm{km}^{2}\right)\end{array}$ & Sol & 16.2 & 18.9 & 18.4 & 19.0 & 19.5 \\
\hline $\begin{array}{l}\text { Motor vehicles density } \\
\text { (No./km) }\end{array}$ & So2 & 378.0 & 452.0 & 496.0 & 521.0 & 541.0 \\
\hline $\begin{array}{l}\text { Days with good air quality } \\
(0-50)\end{array}$ & So3 & 207.0 & 201.0 & 123.0 & 180.0 & 91.0 \\
\hline $\begin{array}{l}\text { Days with poor air quality } \\
(101-200)\end{array}$ & So4 & 24.0 & 18.0 & 4.0 & 25.0 & 59.0 \\
\hline $\mathrm{SO}_{2}\left(\mu \mathrm{g} / \mathrm{m}^{3}\right)$ & En1 & 25.6 & 19.4 & 12.3 & 5.7 & 8.5 \\
\hline $\mathrm{NO}_{2}\left(\mu \mathrm{g} / \mathrm{m}^{3}\right)$ & En2 & 51.8 & 44.5 & 45.1 & 40.0 & 41.0 \\
\hline $\begin{array}{l}\text { Respirable suspended } \\
\text { particulates }\left(\mathrm{PM}_{10}\right), \\
\mathrm{d}<10 \mu \mathrm{m}\end{array}$ & En3 & 63.7 & 57.8 & 59.2 & 52.8 & 63.1 \\
\hline
\end{tabular}
and organization to value conversion.

Table 2: Data sorting from the yearbook of statistics [10]. 
Table 3: Indicator value conversion.

\begin{tabular}{|c|c|c|c|c|c|c|}
\hline Second Grade & No. & 2003 & 2008 & 2011 & 2012 & 2013 \\
\hline Environmental protection investment ('000 mop) & Ec1 & 0.46 & 0.88 & 0.97 & 0.81 & 1.00 \\
\hline Environmental protection and energy saving fund ('000 mop) & Ec2 & 0.00 & 0.00 & 0.00 & 0.51 & 1.00 \\
\hline GDP per capita & Ec3 & 0.20 & 0.44 & 0.76 & 0.87 & 1.00 \\
\hline Environmental assets ('000 mop) & Ec4 & 0.04 & 0.24 & 1.00 & 0.58 & 0.34 \\
\hline Population density ('000/km²) & So1 & 1.00 & 0.86 & 0.88 & 0.85 & 0.83 \\
\hline Motor vehicles density (No./km) & So2 & 1.00 & 0.84 & 0.76 & 0.73 & 0.70 \\
\hline Days with good air quality $(0-50)$ & So3 & 1.00 & 0.97 & 0.59 & 0.87 & 0.44 \\
\hline Days with poor air quality (101-200) & So4 & 0.17 & 0.22 & 1.00 & 0.16 & 0.07 \\
\hline $\mathrm{SO}_{2}(\mu \mathrm{g} / \mathrm{m} 3)$ & En1 & 0.22 & 0.29 & 0.46 & 1.00 & 0.67 \\
\hline $\mathrm{NO}_{2}(\mu \mathrm{g} / \mathrm{m} 3)$ & En2 & 0.77 & 0.90 & 0.89 & 1.00 & 0.97 \\
\hline Respirable suspended particulates $\left(\mathrm{PM}_{10}\right), \mathrm{d}<10 \mu \mathrm{m}$ & En3 & 0.83 & 0.91 & 0.89 & 1.00 & 0.84 \\
\hline
\end{tabular}

Furthermore, aggregated by obtaining weighted sum of normalized criteria values through eqn (2), the final RSIAC-Macau sustainability index of five selected years $(2003,2008,2011,2012,2013)$ is evaluated, which is shown in the Table 4. Since this methodology defines the sustainable state is 1 , the final value of the year, which is closer to 1 , is more sustainable. In year 2003, the RSIAC result is 0.51 , which means it is at the half way of becoming a sustainable city. And this value is gradually increased till year 2011, it reach the peak of 0.77 in that year. After that year, the index of sustainability has begun descending. The index was slowly descended to 0.64 from the year 2011 to the year 2013. That means the sustainability of Macau is going down since 2011 and it will keep going down according to current trend. The city is not walking on a sustainable way.

Table 4: Final sustainability result of five year.

\begin{tabular}{|cc|c|c|c|c|}
\hline RSIAC-Macau & $\mathbf{2 0 0 3}$ & $\mathbf{2 0 0 8}$ & $\mathbf{2 0 1 1}$ & $\mathbf{2 0 1 2}$ & $\mathbf{2 0 1 3}$ \\
$\begin{array}{c}\text { Economic sustainability } \\
\text { Social sustainability }\end{array}$ & 0.14 & 0.33 & 0.68 & 0.63 & 0.74 \\
\hline $\begin{array}{c}\text { Environmental sustainability } \\
\text { Sustainability index }\end{array}$ & 0.66 & 0.64 & 0.80 & 0.56 & 0.34 \\
\hline & 0.51 & 0.60 & 0.77 & 0.73 & 0.64 \\
\hline
\end{tabular}

\section{Discussion and conclusions}

The past few decades have seen rapid change in Macau. Economy has raced ahead, technological advances have brought improved efficiencies and new horizons, and people's lives have improved. All of that change has come at a price, though, in terms of increasing pressures on environment. Steering and decision-making for 
fostering sustainable development of city-regions is a multifaceted task [11]. An advanced approach to evaluate flooring systems based on TBL sustainability criteria has been applied in this paper. The AHP and PCA integrated methodology is a systemic approach to evaluate environmental, economic, and social impacts associated with outdoor air quality. This paper proposed a step-by-step approach that can aggregate the relative weights of different criteria and sub-criteria at different hierarchical levels with the alternatives' scores, to assess the sustainability impacts in Macau.

Further research is still needed. First, this tool could be integrated into a comprehensive planning framework, combining it with scenario analysis, multiattributive evaluation tools, and strategic planning methods. Second, this assessment framework will be used in analysis the studying area of water, noise, waste and energy to contribute a comprehensive sustainability assessment system in Macau. Third, it will work on the decision-makers to identify the political decisions whether they contribute to sustainable development or not.

\section{Acknowledgement}

The research project was supported by the Research Committee of the University of Macau, under Grant No. MYRG106(Y1-L3)-FST12-LIC.

\section{References}

[1] K. P. Bithas and M. Christofakis, Environmentally sustainable cities. Critical review and operational conditions, Sust Dev, vol. 14, no. 3, pp. 177189, Dec. 2005.

[2] O. Ortiz, F. Castells, and G. Sonnemann, Sustainability in the construction industry: A review of recent developments based on LCA, Construction and Building Materials, vol. 23, no. 1, pp. 28-39, Jan. 2009.

[3] D. Devuyst, Linking impact assessment and sustainable development at the local level: the introduction of sustainability assessment systems, Sust Dev, vol. 8, no. 2, pp. 67-78, Dec. 1999.

[4] Yongjun Chen. Take Experience from the History of Urbanization of World for Macau City Development, Asia-Macau Forum, p. 49, 2012.

[5] Y.-J. Lee and C.-M. Huang, Sustainability index for Taipei, Environ Impact Assess Rev, vol. 27, no. 6, pp. 505-521, Dec. 2006.

[6] A. Barrera-Roldán and A. Saldívar-Valdés, Proposal and application of a Sustainable Development Index, Ecological Indicators, vol. 2, no. 3, pp. 251-256, Dec. 2002.

[7] F. I. Khan, R. Sadiq, and T. Husain, GreenPro-I: a risk-based life cycle assessment and decision-making methodology for process plant design, Environmental Modelling \& Software, vol. 17, no. 8, pp. 669-692, Dec. 2002. 
72 Sustainable Development, Vol. 1

[8] R. Sadiq and S. Tesfamariam, Developing environmental indices using fuzzy numbers ordered weighted averaging (FN-OWA) operators, Stoch Environ Res Risk Assess, vol. 22, no. 4, pp. 495-505, May 2008.

[9] S. Vyas and L. Kumaranayake, Constructing socio-economic status indices: how to use principal components analysis, Health Policy Plan, vol. 21, no. 6, pp. 459-468, Nov. 2006.

[10] DSEC, http://www.dsec.gov.mo/Statistic.aspx?lang=en-US\&NodeGuid=d 45bf8ce-2b35-45d9-ab3a-ed645e8af4bb

[11] D. Dörner, The Logic of Failure. Basic Books, 1996. 